\title{
Receptive and Expressive Language in Hindi Speaking Children with Postcochlear Implantation at 6-Month Intervals
}

\author{
Vijay Kumar ${ }^{1,2(0)}$ Rachna Mehta ${ }^{2}$ (1) \\ ${ }^{1}$ Department of Audiology \& Speech Language Pathology, Amity \\ University Gurgaon, Haryana, India \\ 2 Amity Institute of Neuropsychology \& Neurosceience, Amity \\ University, Noida, Uttar Pradesh, India
}

\begin{abstract}
Address for correspondence Rachna Mehta, PhD, Amity Institute of Neuropsychology \& Neuroscience, Amity University, Noida, Uttar Pradesh, India, 201301, India (e-mail: rmehta2@amity.edu).
\end{abstract}

Int Arch Otorhinolaryngol 2021;25(3):e407-e412.

\begin{abstract}
Keywords

- cochlear Implantation

- receptive language

- expressive language

- language assessment

- REELT-3

Introduction Individual variability in the language outcomes of children with cochlear implantation $(\mathrm{Cl})$ is a major concern. In $\mathrm{Cl}$ rehabilitation, there is lack of a protocol regarding uniform post- $\mathrm{Cl}$ language assessment interval duration, which can ensure better understanding of the trajectory of language growth as well as optimize language outcomes by providing feedback in fine tuning the language intervention program.

Objective To evaluate the receptive and expressive language in Hindi speaking children with up to 2 years of $\mathrm{Cl}$ experience using revised receptive-expressive emergent language test-3ed. (REELT-3) at 6 months intervals and to compare it with that of children with normal hearing (NH).

Methods The present study included 192 children divided in 2 groups, 96 children with $\mathrm{Cl}$ (15.8 \pm 6.7 months), and 96 age-matched children with $\mathrm{NH}$ ( $22.3 \pm 7.9$ months). A crosssectional, prospective study design was used to measure the language ability score (LAS) at an interval of 6 months from the time of implantation (TIA), which is 0 to 6 months, 7 to 12 months, 13 to 18 months, and 19 to 24 months of $\mathrm{Cl}$ usage.

Results The two-way analysis of variance revealed that the LAS after 18 months of $\mathrm{Cl}$ usage was similar to $(\mathrm{F}(3,92)=8.63, p=0.19, \mathrm{\eta P2}=0.028)$ that of the children with $\mathrm{NH}$. However, other demographic factors, for instance, gender $(F(3,92)=1.73, p=0.505$, $\eta \mathrm{p} 2=0.002)$, parent's education, $(\mathrm{F}(3,92)=2.05, p=0.937, \mathrm{\eta p} 2=0.031)$, and financial background $(F(3,92)=2.49, p=0.351, \eta p 2=0.076)$ had no major impact on language. Conclusion Eighteen months of $\mathrm{Cl}$ usage duration can potentially stimulate receptive and expressive language up to age-matched children with $\mathrm{NH}$. A protocol of periodic assessment of language, at least of 6 months, may be developed to optimize language outcomes.
\end{abstract}

\section{Introduction}

Cochlear implantation $(\mathrm{CI})$ is globally considered as the standard intervention for severe-to-profound sensory-neural hearing loss in adults and children. ${ }^{1-3}$ Children with congenital or acquired deafness in the early years of life are at a risk of having delayed language comprehension and expression development. ${ }^{1,4}$ Occurrence of congenital deafness restricts received

April 27, 2020

accepted

July 21,2020

published online

September 30, 2020
DOI https://doi.org/ 10.1055/s-0040-1716570. ISSN 1809-9777.

\footnotetext{
(c) 2020. Fundação Otorrinolaringologia. All rights reserved. This is an open access article published by Thieme under the terms of the Creative Commons Attribution-NonDerivative-NonCommercial-License, permitting copying and reproduction so long as the original work is given appropriate credit. Contents may not be used for commercial purposes, or adapted, remixed, transformed or built upon. (https://creativecommons.org/ licenses/by-nc-nd/4.0/)

Thieme Revinter Publicações Ltda., Rua do Matoso 170, Rio de Janeiro, RJ, CEP 20270-135, Brazil
} 
access to acoustic and phonetic elements essential for speech understanding. ${ }^{5}$ The outcome of $\mathrm{CI}$, owing to increased access to the sound provided by it, helps children with deafness to develop language comprehension and expression skills. However, owing to individual and environmental variability, long term outcomes in children with $\mathrm{Cl}$ are not uniform. ${ }^{6,7}$ The age of implantation, surgical techniques, mode of therapy, education level of parents, degree of hearing loss, continuation of therapy, and family involvement are some of the common factors that influence the $\mathrm{CI}$ outcomes. ${ }^{2,8-12}$

The language learning outcome assessment in children with $\mathrm{Cl}$ is an effective way to comment on the success of $\mathrm{CI}$ intervention. ${ }^{3,13}$ The duration of $\mathrm{CI}$ use in early implanted children is a robust predictor of language outcomes; a child with longer $\mathrm{CI}$ usage duration is likely to perform better than children with shorter CI duration. ${ }^{6,14}$ The development of language in children with $\mathrm{CI}$ has been studied using a longitudinal design, in which language assessment was conducted for a group of children with $\mathrm{CI}$ at certain intervals, such as 12 months after implantation, ${ }^{15} 24$ months, ${ }^{1,16}$ 36 months, ${ }^{11} 48$ months, ${ }^{6}$ and 60 months and beyond. ${ }^{13,17}$ In such a scenario, post-CI language gain was compared across the baseline, which is at the time of implantation, to the performance across certain intervals of $\mathrm{CI}$ such as 1,2 , $3,5,10$ and more years. There are varying results of $\mathrm{CI}$ success at these intervals. Nicholas (2007) observed age matched improvement in expressive language by 4.5 years in children who were implanted before 24 months and assessed at 6 and 18 months, respectively. ${ }^{12}$ Connor (2006) investigated vocabulary and speech production outcomes in children with CI semiannually in the $1^{\text {st }}$ year and once for the next 5 years and reported that children who received $\mathrm{CI}$ before 30 months reflected an early burst of language improvement better than children who implanted at a later age. ${ }^{14}$ Geers and Sedey (2011) also found that over $70 \%$ of children with more than 10 years of $\mathrm{CI}$ usage performed closer to children with normal hearing $(\mathrm{NH})$ on single word vocabulary, isolated sentence comprehension and reasoning tasks. ${ }^{16}$

These findings suggest that there is lack of consistency regarding post-CI assessment interval duration. It ranged from 3 months to 5 years intervals. No study was found in which language outcomes in children with $\mathrm{CI}$ was evaluated at fixed, regular intervals using suitable age-matched children with $\mathrm{CI}$ under a counterbalanced, cross-sectional design. It is hypothesized that language assessment of children who were implanted at early age, if assessed periodically at fixed intervals, may yield better language outcomes because the evaluation outcome will also help to fine tune the language intervention program. The findings of this study will facilitate better understanding of the trajectory of language growth in children with $\mathrm{CI}$ as well in customizing the speech-language stimulation plan as per the existing needs of the children within the sensitive period of language learning. Therefore, the aim of the present study was to evaluate the language learning outcome at six-monthly post-CI intervals using revised receptive expressive emergent language test-3ed. (REELT-3), which was recently tested and validated for Hindi speaking children with $\mathrm{CI}^{18}$

Furthermore, most of the studies of CI language assessment and outcome have been done in native Englishspeaking children, which cannot be directly applied to children speaking different languages across the world due to structural linguistic variations across languages. Several studies have reported that non-English speaking children were excluded from the language outcome assessment study due to linguistic variations, which can be a major robust confounding factor. ${ }^{3}$ Morpho-syntactic characteristics of Hindi, one of the widely spoken languages of India, is more complex compared with English. ${ }^{18}$ The morphology of nouns, pronouns, number, and gender agreement of nouns as well as subject-verb agreement is more complex in Hindi as compared with English. ${ }^{19}$ Recent studies suggest that there may be a variable sensitive period for different levels of language. ${ }^{20}$ However, until now, no study has been done to observe the development of language comprehension and production abilities in Hindispeaking children with $\mathrm{CI}$ in a periodic manner and thus that was the another rationale of this study . It is hypothesized that periodic evaluation of the language at an interval of 6 months will enable us to know the language development pattern in Hindi speaking children with CI. Therefore, the present study was designed to evaluate language comprehension and production abilities in (a) Hindi-speaking children with $\mathrm{CI}$; (b) two control groups of children with $\mathrm{NH}$, one with chronologically age-matched children and the other with chronological age corresponding to that of $\mathrm{CI}$ activation; and (c) those with $\mathrm{CI}$ experience of up to 2 years at an interval of 6 months, such as $6,12,18$, and 24 months of the time of implant activation (TIA).

Table 1 Mean age, standard deviation, gender, and percentage of participants across gender for normal hearing, children with cochlear implant and time of implant activation groups

\begin{tabular}{|c|c|c|c|c|c|c|}
\hline & \multicolumn{2}{|c|}{$\begin{array}{l}\text { Children with normal } \\
\text { hearing (NH) } \\
(22.3 \pm 7.9 \text { months) } \\
n=96\end{array}$} & \multicolumn{2}{|c|}{$\begin{array}{l}\text { Children with } \\
\text { cochlear implant }(\mathrm{Cl}) \\
(15.8 \pm 6.7 \text { months }) \\
n=96\end{array}$} & \multicolumn{2}{|c|}{$\begin{array}{l}\text { Time of implant } \\
\text { activation (TIA) } \\
(14.6 \pm 8.8 \text { months) } \\
n=96\end{array}$} \\
\hline & Boys & Girls & Boys & Girls & Boys & Girls \\
\hline Number of Participants & 48 & 48 & 57 & 39 & 57 & 39 \\
\hline Percentage of Participants & $53.1 \%$ & $46.9 \%$ & $60.4 \%$ & $39.6 \%$ & $60.4 . \%$ & $39.6 \%$ \\
\hline
\end{tabular}


Table 2 Mean and standard deviation of the age of time of implant activation groups (age in months)

\begin{tabular}{|l|l|l|l|}
\hline $\begin{array}{l}\text { TIA age } \\
\text { groups }\end{array}$ & Mean age & N (96) & $\begin{array}{l}\text { Std } \\
\text { deviation }\end{array}$ \\
\hline $0-6$ & 5.95 & 24 & 3.34 \\
\hline $7-12$ & 11.5 & 24 & 4.22 \\
\hline $13-18$ & 17.0 & 24 & 1.86 \\
\hline $19-24$ & 21.45 & 24 & 2.43 \\
\hline Total & 13.97 & & 6.5 \\
\hline
\end{tabular}

Abbreviation: TIA, time of implant activation.

\section{Materials and Methods}

\section{Participants}

A total of 96 children with $\mathrm{NH}(22.3 \pm 7.9$ months, 48 boys and 48 girls) with no complaint of speech, language, hearing, intellectual, and developmental delay, and 96 children with CI (15.8 \pm 6.7 months, 57 boys and 39 girls) participated in this study (-Table 1). Another group was formed based on the TIA $(14.6 \pm 8.8$ months $)$; for instance, if a child's CI activation was done at 2 years of chronological age and language assessment was conducted at 3 years of chronological age, then, his TIA age was considered as 1 year (-Table 2). Chronological age-matched controls were selected for the TIA group. All the participants were within 36 months of age and were residents of Delhi, India and nearby regions. (-Table 1) Data were collected over 2 years.

Ethical standards and considerations were maintained and adhered to while selecting the participants for this study. Institutional ethical approval was obtained before the participant's recruitment (AUUP/IEC/2018-AUG/04). The family members/caretakers of each participant were informed about the purpose and procedure of the study and written consent was acquired. Participants under the $\mathrm{NH}$ category were selected based on the following inclusionary criteria: target age of the language assessment tool used in this study (REELT-3); age of the participants below 36 months with no reported history of hearing loss, cognitive, or intellectual deficit, and Hindi as the primary spoken language at home. For the $\mathrm{CI}$ group, the pure tone audiometry finding was more than $85 \mathrm{~dB}$ in the better ear. There should not have been any known history of premorbid neurological illness, psychological disorders, and no other significant sensory and/or cognitive deficits for both groups. Children with CI using sign languages or whose parents were deaf did not participate in this study. Children with $\mathrm{NH}$ were recruited through a random sampling method and purposive sampling was used for the selection of children with $\mathrm{CI}$. Based on the $\mathrm{CI}$ usage duration, the children with $\mathrm{CI}$ were further categorized under 4 categories based on implantation duration (a) between 0 and 6 months (b) 7 and 12 months (c) 13 and 19 months, and (d) 18 and 24 months.

\section{Test Stimuli}

Language comprehension and production were assessed using the REELT-3. ${ }^{21}$ Sixty-six test items of the REELT-3 were chosen for this study. The components of REELT-3 are 2 -fold (a) receptive language and (b) expressive language. In this test, language milestones were used as test items, which were arranged in gradually increasing order of complexity. Some examples of the 66 test items of the REELT-3 are mentioned ahead. In expressive language, \#7 "When hearing voices, does your baby ever vocalize back"? to receptive language \#25 "Does your baby respond to simple commands or requests like ‘Come here!' or 'Let's go!'?” The response was collected in a binary manner, that is, either 'Yes' or 'No'.

\section{Procedure}

The REELT-3 was used to evaluate the receptive and expressive language of children with $\mathrm{CI}$ and $\mathrm{NH}$. Recently, we have published the validation of the REELT-3 in Hindi Speaking children with $\mathrm{CI} .{ }^{18}$ Language ability score (LAS) was obtained for both $\mathrm{NH}$ and $\mathrm{CI}$ groups. The LAS is the combined score of the receptive language ability score (RLAS) and the expressive language ability score (ELAS), which is the standard score obtained after getting a total correct response out of the 66 questions of the REELT-3 under the receptive and expressive categories. Responses were obtained as per the feedback provided by the mother/caregiver as well as, based on the direct observation and interaction during the assessment. The test was administered, analyzed, and interpreted by trained intern volunteers of audiology \& speech therapy. Participants' responses were analyzed and a score of ' 1 ', or ' 0 ' was given for every correct response with or without prompt and incorrect/no response even after prompt response, respectively. ${ }^{21}$ As the questions of the REELT-3 were categorized at an interval of 6 months, the average LAS for the $\mathrm{NH}$ group across each 6 months interval, such as 18 to 24 months, 25 to 30 months, and 31 to 36 months, were obtained and considered as a control group. The LAS of the CI group was obtained at two levels (a) overall LAS of the CI group (of 96 participants), and (b) LAS across four post-CI duration (of 0$6,7-12,13-18$, and 19-24 months of CI usage).

\section{Data Analysis}

The response of each participant was coded, arranged, and analyzed using the IBM SPSS Statistics for Windows, Version 21.0. (IBM Corp., Armond, NY, USA). One-way and two- way analysis of variance (ANOVA) tests were used to check whether LAS across three groups ( $\mathrm{NH}, \mathrm{CI}$, and TIA) and across four post-CI durations varied significantly or not. Tukey's HSD posthoc analysis was done to check out specific relations across the four $\mathrm{CI}$ implant durations.

\section{Results}

The mean LAS of Hindi speaking children with $\mathrm{CI}, \mathrm{NH}$, and TIA was obtained and it was compared across each other. The one-way ANOVA test was used to evaluate whether the language performance of these three groups differ significantly from each other. A significant difference in language 


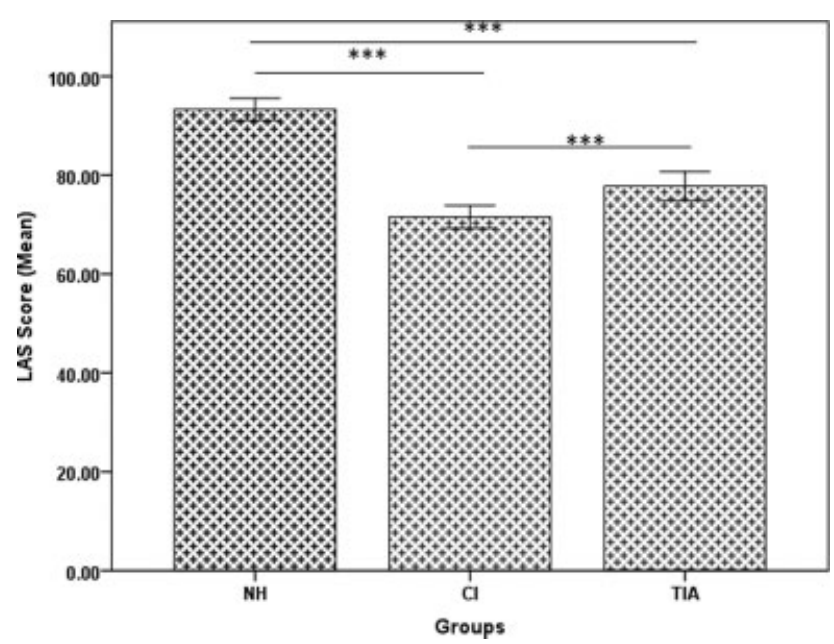

Fig. 1 Bar graph depicting language ability score across normal hearing, cochlear implant and time at implantation activation groups. * inferring statistical significance $(p<0.001)$; Abbreviations as in the text.

performance was obtained across the TIA, $\mathrm{NH}$, and $\mathrm{CI}$ groups $(\mathrm{F}(2,285)=79.530, p=0.001, \mathrm{\eta p} 2=0.358)$ (-Fig. 1). Moreover, Tukey's HSD posthoc analysis was done to test the significance between $\mathrm{NH}$ and $\mathrm{CI}, \mathrm{NH}$ and TIA, TIA, and $\mathrm{CI}$ groups. It was observed that language performance differed significantly across all three conditions; (a) the language performance of children with $\mathrm{NH}$ was significantly better than that of children with $\mathrm{CI}(\mathrm{F}(1,190)=21.89, p=0.001$, пp2 $=0.495$ ); (b) similarly, group-wise the children with up to 2 years of TIA performed poorer than the age-matched children with $\mathrm{NH}^{14}$ for language performance task $(\mathrm{F}(1,190)=15.89$, $p=0.001, \eta p 2=.289$ ), and (c) children with up to two years of TIA performed better on language performance tasks than the children with $\mathrm{CI}(\mathrm{F}(1,190)=6.273, p=0.004, \mathrm{np} 2=0.037)$ (-Fig. 1).

The LAS of the TIA group was compared across $4 \mathrm{CI}$ usage windows, that are 0 to 6 months, 7 to 12 months, 13 to

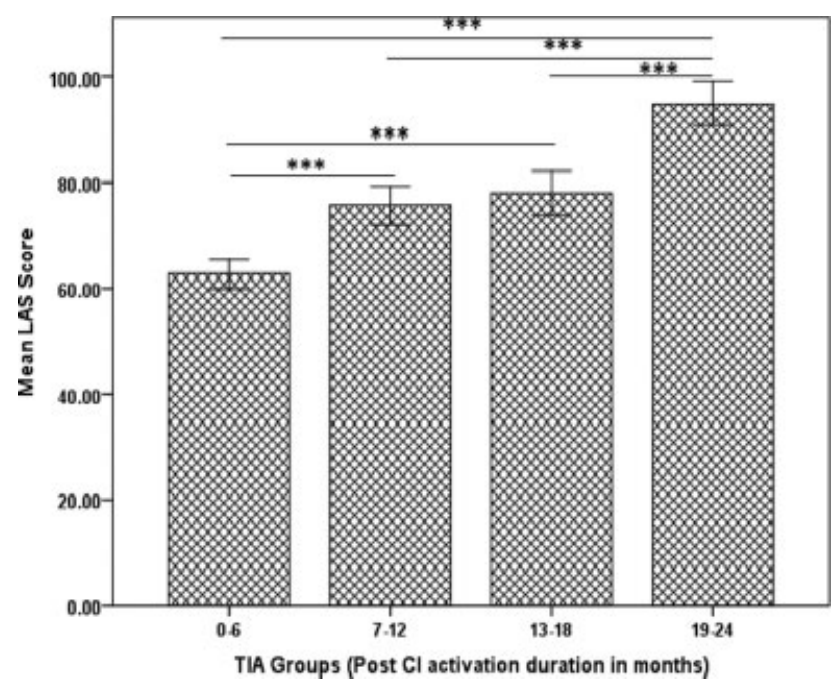

Fig. 2 Bar graph showing language ability score across four groups of time of implant activation (in months). * inferring statistical significance $(p<0.01)$; Abbreviations as in the text.

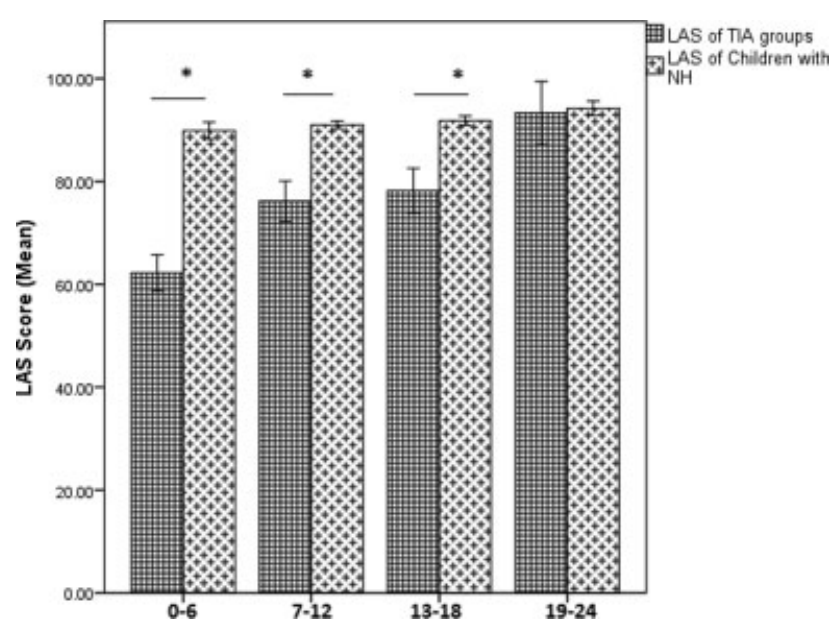

Fig. 3 Bar graph reflecting language ability score across normal hearing, cochlear implant and time of implant activation groups across gender. ${ }^{*}$ inferring statistical significance $(p<0.05)$; Abbreviations as in the text.

18 months, and 19 to 24 months. One-way ANOVA analysis was done to test whether the language performance of these four groups significantly varied from each other. It was observed that language performance across four $\mathrm{CI}$ usage duration was significantly different across each other $(F(3$, $92)=6.620, p=0.001, \mathrm{np} 2=0.178$ ) (-Fig. 2).Tukey's HSD posthoc analysis was done to identify the rate of improvement across four CI usage durations and to test whether these durations differed significantly. It was observed that the language performance of the TIA group having more than 18 months of $\mathrm{CI}$ usage was significantly higher than TIA groups of 0 to 6,7 to 12 , and 12 to 18 months. However, no significant difference was observed between children having CI usage experience of 7 to 12 months and 13 to 18 months (-Fig. 2).

Besides, the LAS of children of the TIA group from 0 to 2 years of $\mathrm{CI}$ usage were compared across age-matched children with NH. The two-way ANOVA revealed that the language performance of children with $\mathrm{CI}$ for 0 to 6 months durations was significantly lower than children with $\mathrm{NH}(\mathrm{F}$ $(3,92)=30.1, p=0.008, n p 2=0.028)$ (-Fig. 3), while in the 18 to 24 months group, the language performance in the $\mathrm{CI}$ usage approached that of the $\mathrm{NH}$ group $(\mathrm{F}(3,92)=8.63$, $p=0.19$, пр2 $=0.028$ ). Language development pattern in boys and girls with $\mathrm{CI}$ was also evaluated for the $\mathrm{NH}, \mathrm{CI}$, and TIA groups. The two-way ANOVA test was computed to test whether the language performance of children with $\mathrm{CI}$ was different from each other across gender during four phases of assessment at 6 months interval. No significant difference in overall language gain across boys and girls was obtained for $\mathrm{NH}, \mathrm{CI}$, and TIA $(\mathrm{F}(3,92)=1.73, p=0.505$, пр2 = 0.002) (-Fig. 4).

Similarly, the language outcome was tested across the socioeconomic-educational perspective. Parents of the $\mathrm{CI}$ group who had less than 12 years of formal education were compared across more than 12 years of educated parents. The one-way ANOVA test was computed to test whether the language performance of these three groups 


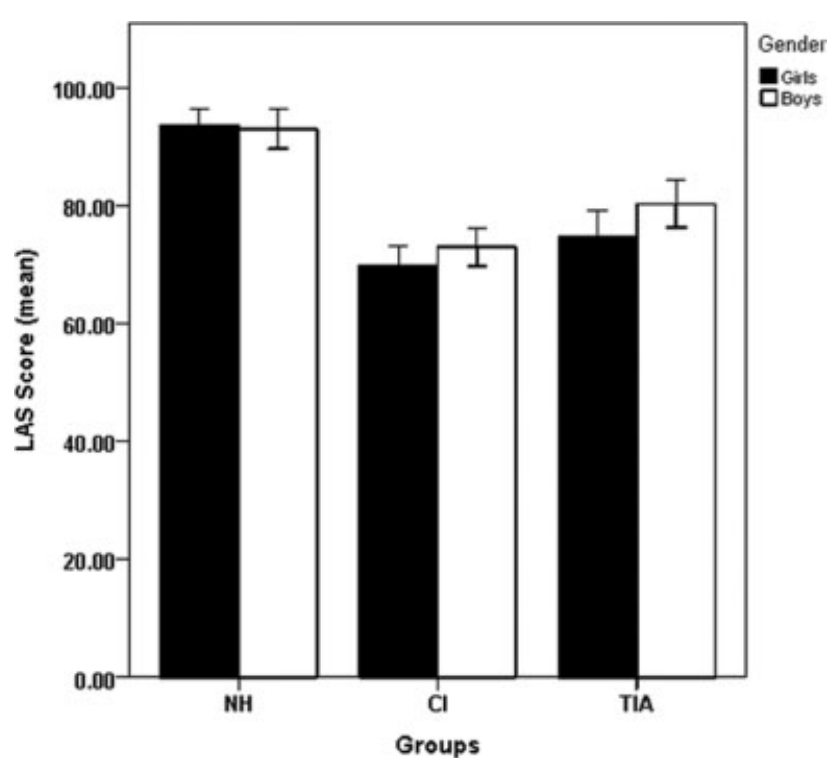

Fig. 4 Bar graph reflecting language ability score of children with normal hearing across children with cochlear implant of time of implant activation groups across four assessment conditions at an interval of 6 months. ${ }^{*}$ inferring statistical significance $(p<0.05)$; Abbreviations as in the text.

differed, and it was observed that the educational background of parents does not significantly influence language outcomes $(\mathrm{F}(3,92)=2.05, p=0.937, \mathrm{np} 2=0.031)$. Parents of the $\mathrm{Cl}$ group whose monthly income was lower than the Indian Rupees 10,000 were compared to parents who earned more than the Indian Rupees 10,000. The one-way ANOVA test was computed to test whether the language performance of these two groups differed significantly, and it was also observed that the financial background of parents does not influence language outcomes significantly in children with $\mathrm{Cl}(\mathrm{F}(3,92)=2.49, p=0.351, \mathrm{np} 2=0.076)$.

\section{Discussion}

In the present study, language comprehension and expression abilities were tested using the REELT-3 to compare $\mathrm{NH}$, $\mathrm{CI}$, and TIA Hindi speaking children. It was observed that the LAS of the CI group was significantly different compared with that of the NH group; however, no significant difference was obtained across the CI \& TIA and TIA \& NH groups. Thus, it can be inferred that the language development in the TIA group occurred in the same patterns as that of age-matched $\mathrm{NH}$ children. The mean age of the TIA group was 21.45 months, which suggests that auditory stimulation of more than 14 months is critically required and enough to bridge the gap in language performance between the $\mathrm{Cl}$ and $\mathrm{NH}$ groups. These findings suggest that the prolonged auditory period in children with $\mathrm{Cl}$ increases the morphological and phonological awareness skills that are requisite for language development and expression. ${ }^{1,14}$ Moreover, longer duration of $\mathrm{CI}$ usage enhances mother-child interaction and helps in building additional social-cognitive connection with the surroundings, which is essential for language development. ${ }^{14}$
Depending on the duration of $\mathrm{Cl}$ usage, the development of language learning was also measured across four time frames, between 0 and 6 months; 7 and 12 months; 13 and 19 months; and 18 and 24 months. The results revealed that the language performance of $\mathrm{Cl}$ children increased significantly after 18 months of $\mathrm{CI}$ usage compared with the other three time frames. Moreover, a significant difference was also observed for language development between 0 and 6 months and 13 and 18 months of the TIA group. This finding suggests that a minimum of 1 year is required to observe a significant difference in language development among various TIA groups, thus justifying the need for early implantation. ${ }^{12,22,23}$ Early implantation ensured early access to sound for the $\mathrm{Cl}$ children resulting in a shorter sound deprivation period, which is required for language development. ${ }^{11}$ It was also observed that early $\mathrm{CI}$ ensures auditory neural reorganization corresponding to exposure of sound or verbal input. ${ }^{24,25}$ These findings also support the existence of an early sensitive period through early and ongoing plasticity of central auditory pathways for receptive and expressive language learning in children with CI. ${ }^{14}$ Furthermore, the present study also supports the age range of less than 2.5 years as the most sensitive critical age for neuroplasticity and central auditory nerve development responsible for the growth of language, as the mean age of the TIA group in this study was 14.6 months. ${ }^{25,26}$ However, the critical time range of less than 2.5 years may vary for different speech and language components. ${ }^{27}$ Also, the results revealed that even after 24 months of $\mathrm{CI}$ use, the group-wise gap on language performance tasks was not bridged completely between the Hindi speaking $\mathrm{CI}$ and $\mathrm{NH}$ groups. However, after 18 months of $\mathrm{CI}$ usage, the language performance of children with $\mathrm{Cl}$ appeared in the range of that of children with $\mathrm{NH}$. Owing to morphosyntactic complexity, especially in person, gender, number, subject-verb agreement, etc., language learning in children with $\mathrm{CI}$ cannot completely approach the learning abilities of children with $\mathrm{NH}$. This further justifies the need for a longitudinal study for more than 24 months of activation of $\mathrm{CI}$.

Furthermore, the language performance was also compared among the $\mathrm{CI}$, TIA, and NH groups across gender, family income, and parental education, separately. The rationale for doing such analysis was to check whether these confounding variables have any impact on the outcome of the present study. No significant difference was observed for any of these three conditions. Prolonged CI usages and early implantation enables re-networking of the central auditory pathway, which is essential for intact language comprehension and production. ${ }^{25}$ Thus, it may be possible that demographic-related issues, such as gender, family income, and parental education, would not have impacted the language learning outcomes. Moreover, although the status of language in children in the $\mathrm{CI}$ and $\mathrm{NH}$ groups was quantified using parents' feedback along with direct observation and interaction, the potential bias in the parents' information may not be ruled out completely. 


\section{Conclusion}

The present study reveals that language development in children with $\mathrm{CI}$ improves significantly during the $2^{\text {nd }}$ year of CI usage. The present findings justify the need for early implantation to ensure a reduced sound deprivation phase. Periodic assessment of language outcomes at an interval of 6-months in the children with CI can facilitate the understanding of the pattern and trajectory of language development. The inclusion of more language domains for assessment beyond 2 years, using a longitudinal design, may yield better outcomes. From a theoretical point of view, this study allows us to understand the nature of linguistic difficulties in children with $\mathrm{CI}$ that may manifest across the different duration of $\mathrm{Cl}$ usage across languages. Clinically, the dynamics of language development in children with $\mathrm{CI}$ can be used as feedback in developing a target-based therapeutic intervention plan.

\section{Conflict of Interests}

The authors declare that there is no conflict of interests.

\section{Acknowledgment}

The support and research facilities provided by the Amity University are acknowledged.

\section{References}

1 Caselli MC, Rinaldi P, Varuzza C, Giuliani A, Burdo S. Cochlear implant in the second year of life: lexical and grammatical outcomes. J Speech Lang Hear Res 2012;55(02):382-394

2 Pisoni DB, Kronenberger WG, Harris MS, Moberly AC. Three challenges for future research on cochlear implants. World J Otorhinolaryngol Head Neck Surg 2018;3(04):240-254

3 Baldassari CM, Schmidt C, Schubert CM, Srinivasan P, Dodson KM, Sismanis A. Receptive language outcomes in children after cochlear implantation. Otolaryngol Head Neck Surg 2009;140(01): 114-119

4 Levitt H, McGarr N, Geffner D. Development of language and communication skills in hearing-impaired children. Introduction. ASHA Monogr 1987;(26):1-8

5 Svirsky MA, Teoh S-W, Neuburger H. Development of language and speech perception in congenitally, profoundly deaf children as a function of age at cochlear implantation. Audiol Neurotol 2004;9(04):224-233

6 Bradham T, Jones J. Cochlear implant candidacy in the United States: prevalence in children 12 months to 6 years of age. Int J Pediatr Otorhinolaryngol 2008;72(07):1023-1028

7 Cruz I, Quittner AL, Marker C, DesJardin JL, Team CICDaCI Investigative Team. Identification of effective strategies to promote language in deaf children with cochlear implants. Child Dev 2013;84(02):543-559

8 Tomblin JB, Barker BA, Spencer LJ, Zhang X, Gantz BJ. The effect of age at cochlear implant initial stimulation on expressive language growth in infants and toddlers. J Speech Lang Hear Res 2005;48 (04):853-867
9 Brito Rd, Bittencourt AG, Tsuji RK, Magnan J, Bento RF. Cochlear implantation through the middle fossa: an anatomic study for a novel technique. Acta Otolaryngol 2013;133(09):905-909

10 Leigh J, Dettman S, Dowell R, Briggs R. Communication development in children who receive a cochlear implant by 12 months of age. Otol Neurotol 2013;34(03):443-450

11 Geers AE. Speech, language, and reading skills after early cochlear implantation. Arch Otolaryngol Head Neck Surg 2004;130(05): 634-638

12 Nicholas JG, Geers AE. Will they catch up? The role of age at cochlear implantation in the spoken language development of children with severe to profound hearing loss. J Speech Lang Hear Res 2007;50(04):1048-1062

13 Ruben RJ. Language development in the pediatric cochlear implant patient. Laryngoscope Investig Otolaryngol 2018;3(03):209-213

14 Connor CM, Craig HK, Raudenbush SW, Heavner K, Zwolan TA. The age at which young deaf children receive cochlear implants and their vocabulary and speech-production growth: is there an added value for early implantation? Ear Hear 2006;27(06):628-644

15 Miyamoto RT, Hay-McCutcheon MJ, Kirk KI, Houston DM, Bergeson-Dana T. Language skills of profoundly deaf children who received cochlear implants under 12 months of age: a preliminary study. Acta Otolaryngol 2008;128(04):373-377

16 Geers AE, Sedey AL. Language and verbal reasoning skills in adolescents with 10 or more years of cochlear implant experience. Ear Hear 2011;32(01):39S-48S

17 Geers AE. Factors Affecting the Development of Speech, Language, and Literacy in Children With Early Cochlear Implantation. Lang Speech Hear Serv Sch 2002;33(03):172-183

18 Kumar V, Mehta R. Adaptation and validation of receptive expressive emergent Language Test-3: Evidence from Hindi speaking children with cochlear implant. Int J Pediatr Otorhinolaryngol 2020;132:109891

19 Dayal V. Incorporation: Morpho-syntactic vs. semantic considerations. The syntax and semantics of pseudo-incorporation: Brill; 2015:47-87

20 Houston DM, Miyamoto RT. Effects of early auditory experience on word learning and speech perception in deaf children with cochlear implants: implications for sensitive periods of language development. Otol Neurotol 2010;31(08):1248-1253

21 Bzoch KR, League R, Brown VL. Receptive-expressive Emergent Language Test: Examiner's Manual: Pro-ed. 2003

22 Clark JH, Wang N-Y, Riley AWCDaCI Investigative Team. et al; $\{\#, 46\}$. Timing of cochlear implantation and parents' global ratings of children's health and development. Otol Neurotol 2012;33(04):545-552

23 Ertmer DJ, Young NM, Nathani S. Profiles of vocal development in young cochlear implant recipients. J Speech Lang Hear Res 2007; 50(02):393-407

24 Gordon KA, Papsin BC, Harrison RV. Activity-dependent developmental plasticity of the auditory brain stem in children who use cochlear implants. Ear Hear 2003;24(06):485-500

25 Sharma A, Dorman MF, Spahr AJ. A sensitive period for the development of the central auditory system in children with cochlear implants: implications for age of implantation. Ear Hear 2002;23(06):532-539

26 Locke JL. A theory of neurolinguistic development. Brain Lang 1997;58(02):265-326

27 Bates E. Language and the infant brain. J Commun Disord 1999;32 (04):195-205 